\title{
Power losses estimation and heat distribution in three-phase inverter using IGBT semiconductors
}

\author{
PATRIK RESUTIK, SLAVOMIR KASCAK \\ Department of Mechatronics and Electronics \\ University of Zilina \\ 01026 Zilina Slovakia \\ SLOVAKIA
}

\begin{abstract}
Power loss estimation is a very crucial step in the design of power inverters and other power converters. In this paper, the estimation of power losses using MATLAB Simulink is presented. This approach allows fast estimation of losses and can lower the design time of the cooling system. With the use of a simulation approach, different parameters can be simulated to estimate losses and design the best cooling solution accurately. Characteristics of the used semiconductor in this case IGBT is used and imported to the electro-thermal simulation. This simulation consists of two main parts. The first component calculates semiconductor losses depends on the provided characteristics of the used device and his temperature. The second model calculates temperature based on the thermal model and losses produced by the first part of the simulation. Results in the form of the losses are implemented to the heat distribution simulation using Fusion 360 to simulate the temperature distribution of the used heatsink.
\end{abstract}

Key-Words: - Power losses, IGBT, Inverter, Heat distribution, MATLAB, FOC

Received: February 4, 2020. Revised: June 14, 2020. Accepted: June 29, 2020. Published: July 19, 2020.

\section{Introduction}

Innovation in the field of power electronics leads to a significant reduction of the power device dimensions The miniaturization results in much higher heat flux generated by semiconductors. For ensuring the reliability and performance of the design, the recommended junction temperature of the semiconductor cannot be exceeded. Therefore, electrical and thermal modeling is of great interest to ensure the proper function of the device [1], [2]. This paper focuses on electro-thermal simulation in three-phase inverters based on IGBT semiconductor switches. There are many options to estimate power losses generated by power semiconductors, from which they can be chosen.

The first direct calculation can be used, involving RMS and AV values of voltage and current. By this method, all types of power losses can be estimated [3]. Second, the indirect calculation of the losses using instantaneous values of the voltage and current can be used. [4]. For better estimations, static and dynamic models of the used switch can be used to estimate power losses accurately. The precision of this result depending on the accuracy of the used model [5]. Another approach can be selected using a finite element approach to estimate temperature and flux distribution [6], [7], [8]. Finally, the experimental measurement can be used to estimate losses and cooling, but this requires a physical sample of the design [9],[10].

Many publications use only equations or only the static parameters of the used semiconductor [11-15]. If dynamic parameters are used, they use it only for one temperature or a constant value of the switch current. In this publication, instantaneous values of the collector current $\mathrm{I}_{\mathrm{C}}$ and collector-emitter voltage $\mathrm{V}_{\mathrm{CE}}$ are used for conductive losses calculation. For switching losses, instantaneous values of turn-on and turn-off switching losses are used. For heat dissipation, the thermal model is created in the next step. This model uses values of thermal resistance of the device from manufacturer datasheet, and the value of thermal resistance of the used heatsink. In MATLAB-Simulink, these two models are fused. The output of the electrical model, which is the total power loss of the device, is fed into the thermal model. The thermal model uses this value of power loss to calculate the temperature of the components present in the thermal model. The output of the thermal model is fed back to the electrical model, so the simulation could use actual temperature to losses calculation because parameters of the semiconductor switch are temperature dependent. Finally, the average steady-state losses produced by MATLAB-Simulink simulation is used in the next software. For the heat distribution, the program 
Fusion 360 is used. The results of all the simulations and calculations are in this paper.

\section{Losses estimation using MATLAB - Simulink}

For loss estimation in the three-phase inverter, the electro-thermal model in MATLAB-Simulink was created. The main part of the model is a three-phase inverter build from IGBT semiconductors. For controlling inverter and generating proper firing pulses, field-oriented Control (FOC) is used [16]. The load for the model is represented by the induction motor. For loss calculation, characteristics of used semiconductors were added to the switch model. Included characteristics are collector current as a function of saturation voltage and temperature $I_{C}=f\left(V_{T c e}, T\right)$, and switching losses vs. collector current and temperature, $E_{O F F}=f\left(I_{C}, T\right)$, and $E_{O N}=f\left(I_{C}, T\right)$. For the body diode losses characteristic of forward voltage vs. forward current and temperature $I_{F}=f\left(V_{D f}, T\right)$ involving recovery losses was used. All characteristics consist of two curves for different temperatures, in this case, for $25^{\circ} \mathrm{C}$ and $175^{\circ} \mathrm{C}$. Different temperatures can be used, too, depending on manufacturer specifications. Characteristics can be seen in Fig. 1, and Fig. 2. For this model, IGBT FGY40T120SMD was used, so imported characteristics are from this device datasheet. If another device is selected, the mentioned characteristics need to be imported for that selected device. Losses generated by this model are used by the thermal model.

The thermal model uses thermal resistance of the heatsink and heat-conducting pad to estimate the temperature at different parts of the model, as junction, case, and heatsink. The value of actual junction temperature is fed back to the electrical model, where it is used to estimate turn on and turn off energies and forward voltages of IGBT and internal diode at this temperature.

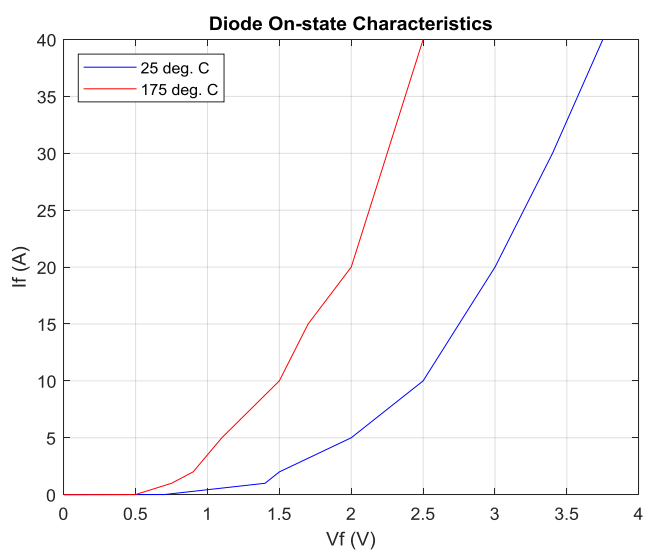

Fig.1 Body diode forward voltage in used IGBT
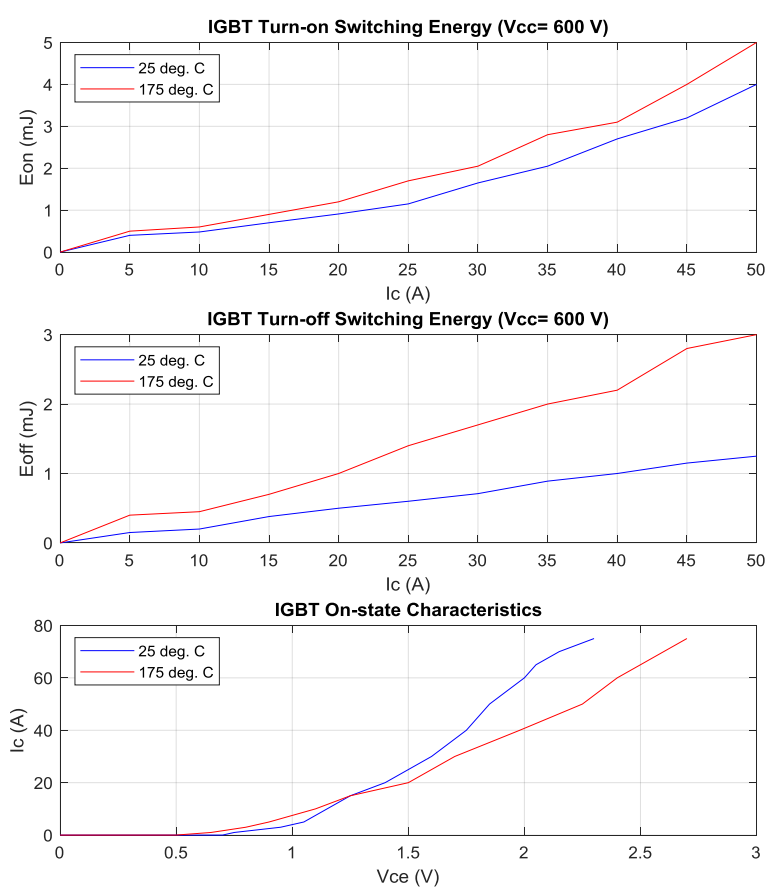

Fig.2 IGBT characteristics in MATLAB model

In the simulation, $7500 \mathrm{~W}$ asynchronous motor was used. Motor shaft is spin-up to the nominal speed, which is $1500 \mathrm{rpm}$. After two seconds, the nominal load is connected to the shaft of the motor. In Fig.3, simulated output representing instantaneous losses of the inverter is shown.

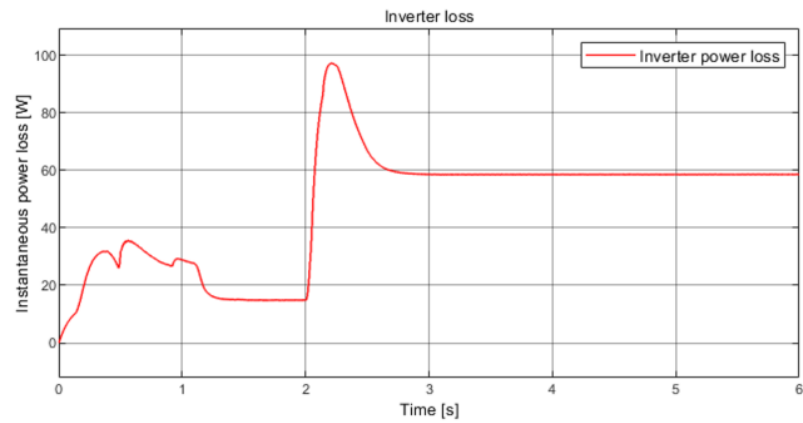

Fig. 3 Waveform of the inverter losses from the simulation

The steady-state losses at full load are 59W. Individual parts of the losses are summarized in Table 1 .

\begin{tabular}{|c|c|c|c|}
\hline Device & Conduction & Switching & Overall \\
\hline \multicolumn{4}{|c|}{ FGY40T120SMD } \\
\hline Transistor & $6.5 \mathrm{~W}$ & $1.8 \mathrm{~W}$ & \multirow{2}{*}{$59 \mathrm{~W}$} \\
\hline Diode & $1.4 \mathrm{~W}$ & $0.15 \mathrm{~W}$ & \\
\hline \multicolumn{4}{|c}{ Table 1 Simulated losses } \\
\end{tabular}

In comparison, power losses were calculated with the use of mathematical methods according to [12], [13], with the same parameters as used in the 
simulated system. The results from these mathematical calculations are shown in the next table.

\begin{tabular}{|c|c|c|c|}
\hline Device & Conduction & Switching & Overall \\
\hline \multicolumn{3}{|c|}{ FGY40T120SMD } \\
\hline Transistor & $8.1 \mathrm{~W}$ & $2 \mathrm{~W}$ & \multirow{2}{*}{$84 \mathrm{~W}$} \\
\hline Diode & $3.6 \mathrm{~W}$ & $0.3 \mathrm{~W}$ & \\
\hline $\begin{array}{c}\text { Relative } \\
\text { error } \\
\text { Transistor }\end{array}$ & $+19,7 \%$ & $+10 \%$ & \multirow{2}{*}{$+29,7 \%$} \\
\cline { 1 - 3 } $\begin{array}{c}\text { Relative } \\
\text { error } \\
\text { Diode }\end{array}$ & $+61,1 \%$ & $+50 \%$ & \\
\hline
\end{tabular}

Table 2 Calculated losses

As can be seen in Tab.1 and Tab.2, there is a difference in simulated and calculated losses. This error is expressed by the relative error in percentage. The calculated losses are higher against simulated ones because of the constant values of energies and voltage drops used in the mathematical approach. Simulation is using instantaneous values of the switching on and off energies, and saturation voltage $V_{T c e}$ derived from device current and temperature conditions.

\section{Temperature calculation and simulation}

\subsection{Calculated temperature}

When the losses generated by inverter are known from simulation, calculation of temperatures was performed with the help of the thermal model. The thermal resistance of IGBT and diode was used from datasheet and thermal resistance if the heatsink was experimentally measured. For the experiment, power resistors were mounted at the heatsink. These resistors simulated the power dissipation of the transistors. Heatsink with multiple temperature sensors was put to a controlled environment, with no airflow. When the temperature of the heatsink stabilizes, calculation of the heatsink thermal resistance can be calculated based on heatsink temperature, ambient temperature, and the known power losses. For this calculation, equation (1) was used.

$$
R_{h a}=\frac{T_{h}-T_{a}}{P_{T O T}}
$$

Where $T_{h}$ and $T_{a}$ represent heatsink and ambient temperature, respectively, $\mathrm{P}_{\text {TOT }}$ is heat dissipation power, and $\mathrm{R}_{\mathrm{ha}}$ represents heatsink thermal resistance. The measured value of heatsink resistance $R_{\text {ha }}$ is $0.65^{\circ} \mathrm{C} / \mathrm{W}$. When we know the thermal resistance of the heatsink, IGBT, diode, and dissipated power, we can calculate the steady-state thermal model with the use of the next equations:

$$
\begin{aligned}
& T_{h}=T_{a}+P_{T O T} \cdot R_{h a} \\
& T_{c}=T_{h}+\frac{P_{T O T}}{6} \cdot R_{c h} \\
& T_{j}=T_{c}+\frac{P_{T O T}}{6} \cdot R_{j c I G B T}
\end{aligned}
$$

Where $T_{h}, T_{a}, T_{c}, T_{j}$ represents heatsink, ambient case, and junction temperature respectively, $\mathrm{P}_{\text {TOT }}$ is a power loss and $\mathrm{R}_{\mathrm{ha}}, \mathrm{R}_{\mathrm{ch}}, \mathrm{R}_{\mathrm{jcIGBT}}$ is the heatsink, case and junction thermal resistance respectively. The device uses six IGBT switches with diodes, so the steady-state thermal model was created. Every switch has its source of heat, separated from the case by Junction-Case thermal resistance. To ensure the electrical isolation between IGBT and the heatsink, a thermal isolation pad was used under every IGBT. This is represented by the thermal resistance of the insulating pad $R_{\text {ch. }}$ Then, all devices are connected to the one point, represented by the thermal resistance of the heatsink. For steady-state calculation, the ambient temperature was chosen to be $30^{\circ} \mathrm{C}$.

\subsection{MATLAB Simulink thermal model}

MATLAB-Simulink thermal model simulation is part of the simulated model. This part calculates temperatures from the simulated power losses provided by the loss model. Fig. 4 shows the used thermal model in the MATLAB-Simulink interface.

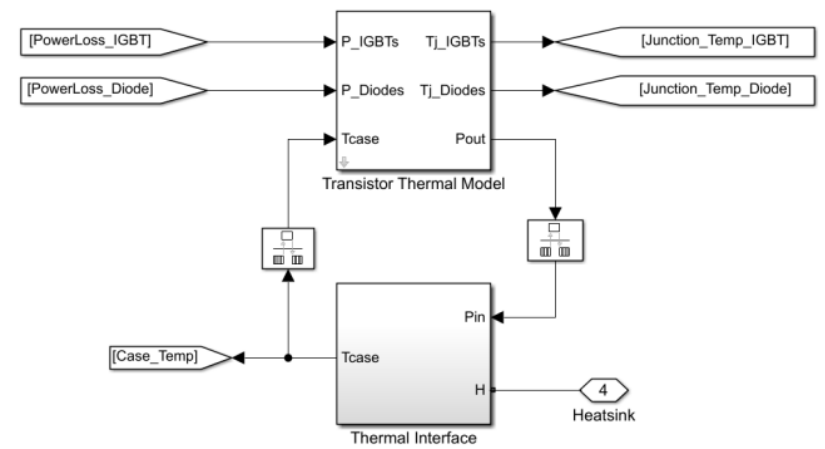

Fig.4 Inverter temperature from MATLAB thermal model

As can be seen in Fig. 4, losses from the IGBT and diode are used to calculate the junction temperature of the IGBT and the diode. Case temperature is calculated too. In Fig.5 average output power can be seen represented by the green line at the top of the graph. At the bottom graph, 
red, orange, and blue lines represent the temperature at heatsink, case, and junction, respectively. The exponential rise of temperature is given by the thermal capacitance of the system.

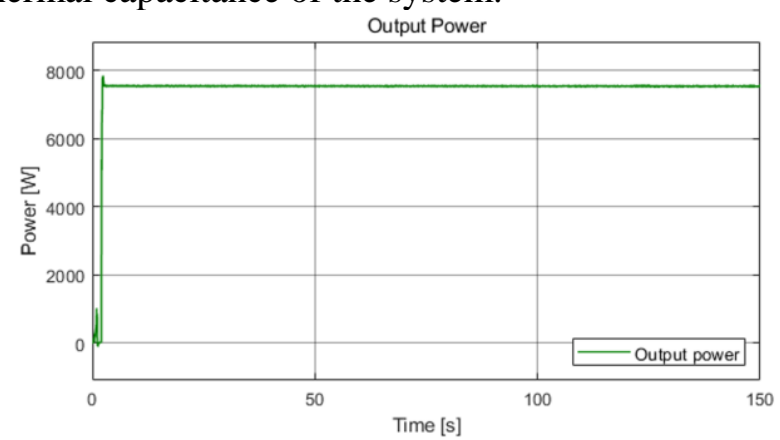

Temperatures

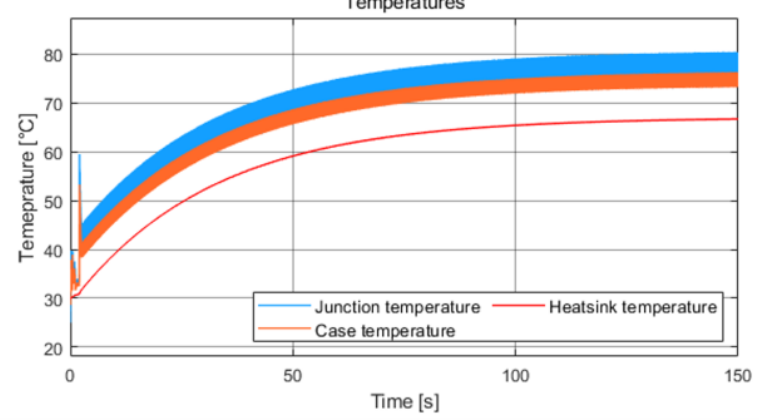

Fig.5 Inverter temperature from MATLAB thermal model

\subsection{Fusion 360 thermal distribution simulation}

For the heat distribution, Fusion 360 was used. The first step is to draw a model of the heatsink in the sketch mode. Next, the IGBT model needs to be created. This model was designed as a three-part component, with a separated junction, backplate, and case parts. This separation leads to a better determination of the heat spreading in a component. After all partial models are completed, they are joined together to one model shown in Fig.6. When the model is completed, the next step is a definition of the materials. The program offers a wide range of materials to choose from. All materials have defined fundamental properties. For the heatsink, aluminum was chosen, the IGBT case was defined as epoxy resin. Finally, for backplate and junction, copper was selected. This simplification can be made according to the construction of the IGBTs [17]. When all materials are defined, the next step is load definition.

Load represents where the heat is generated, or how the part can dissipate heat. The junction of each transistor was defined as an internal heat source because this is the place where all the losses originate. Values for every junction are $9.8 \mathrm{~W}$, which gives $59 \mathrm{~W}$ in total as simulated in the MATLAB loss model. Now, areas with convection and radiation must be defined. The whole area of the heatsink has a convection value of $3 \mathrm{~W} / \mathrm{m}^{2} \mathrm{~K}$ defined. This value represents the horizontal plane in the air. If there is airflow around the fins of the heatsink, these values need to be adjusted accordingly. The emissivity of the heatsink was set to 0.08 because of the shiny property of the aluminum. The case has emissivity set to 0.98 .

There is no need to know the value of the thermal resistance of the used heatsink because the program calculates it from provided geometry and data.

The final step is selecting mesh. User can select own density of the mesh, or let the program select mesh size. The program selects an optimum value for low simulation time and results. When the simulation is done, the program shows temperature spread across the heatsink. For the investigation, the point probe can be used to observe temperatures at critical points of the system. This program only simulates the steady-state temperature distribution. If the parameter is changed, simulation must be run again.

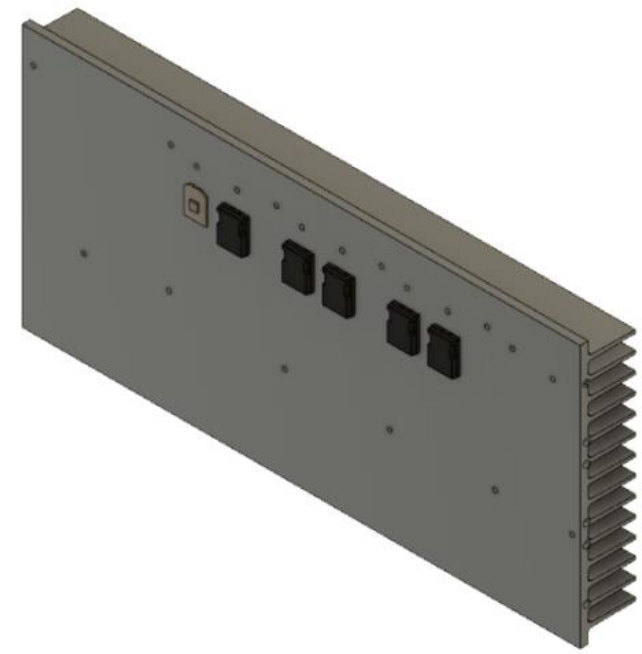

Fig.6 3D model of cooling in Fusion 360

The simulation of designed heatsink for the inverter application can be seen in the next Figure. 


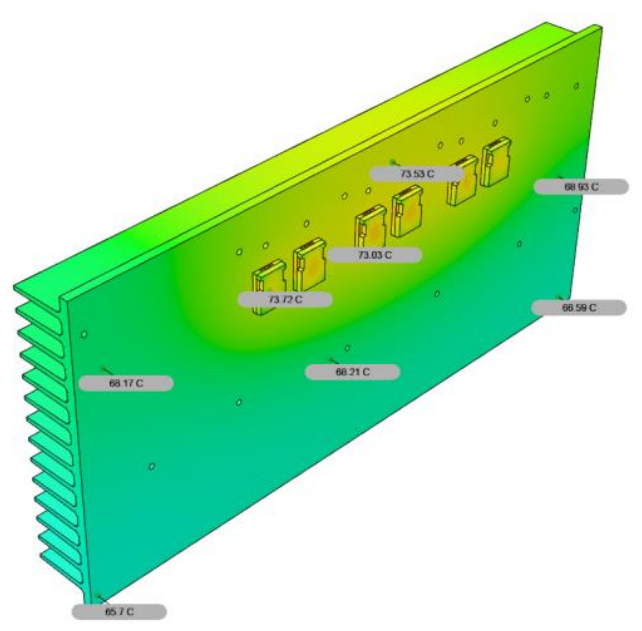

Fig.7 output of the thermal simulation from the

Fusion 360

\subsection{Comparison of results}

Three methods were used to estimate temperatures in the three-phase inverter. First is a basic steady-state thermal model, the second method uses MATLAB thermal model described in chapter 3.2 to estimate temperatures, and finally, Fusion 360 was used to thermal model analysis. The results are shown in Table 3, and as can be seen, results are nearly the same.

\begin{tabular}{|l|c|c|c|}
\hline Point & Heatsink & Case & Junction \\
\hline $\begin{array}{c}\text { Calculation } \\
(3.1)\end{array}$ & $68.4^{\circ} \mathrm{C}$ & $72.3^{\circ} \mathrm{C}$ & $74^{\circ} \mathrm{C}$ \\
\hline $\begin{array}{c}\text { MATLAB } \\
\text { simulation } \\
(3.2)\end{array}$ & $68.2^{\circ} \mathrm{C}$ & - & $76^{\circ} \mathrm{C}$ \\
\hline $\begin{array}{c}\text { Fusion } 360 \\
(3.3)\end{array}$ & $68.5^{\circ} \mathrm{C}$ & $73^{\circ} \mathrm{C}$ & $76.5^{\circ} \mathrm{C}$ \\
\hline
\end{tabular}

Table 3 Overview of calculated and simulated temperatures at power losses of $59 \mathrm{~W}$

\section{Conclusion}

This paper discusses simulation loss determination using MATLAB-Simulink. This model can simulate different used IGBT switches with different parameters. The model can calculate power losses and temperature at different points in the system. Most important, this simulation is dynamic so that transient can be simulated and analyzed too. After simulating power loss value was used to calculate temperature with the use of a static thermal model. Finally, Fusion 360 was used to simulate heat spreading in the inverter model. With the use of this program and knowing the power losses, we can easily model and design a suitable heatsink and cooling solution for the target application. The MATLAB-Simulink thermal model can be implemented for various types of converter topologies and different types of switches or different modulation techniques if needed. The flexibility of this model gives a big advantage in cooling design and part selection for application based on the best price/performance ratio. Users can implement characteristics of different types of transistors and run simulations for all defined kinds. Then, based on the simulation results, the best type can be selected for the target application. In future work, the mathematical and simulated results will be experimentally verified at the inverter sample. Temperature distribution will be measured, too, with the use of the thermal imaging to compare results to Fusion 360 simulation, and surface mounted temperature sensors to minimize measurement error.

\section{Acknowledgment:}

This work was supported by projects: KEGA project No. 027ŽU-4/2018, APVV-15-0571: Research of the optimum energy flow control in the electric vehicle system, ITMS 26220220078 -Research of high effective components of electric drive systems of urban electric vehicles

\section{References:}

[1] O.S. Senturk, L. Helle, S. Munk-Nielsen, P. Rodriguez, and R.Teodorescu, "Electrothermal Modeling for Junction Temperature Cycling-Based Lifetime Prediction of a PressPack IGBT 3L-NPCVSC Applied to Large Wind Turbines," in IEEE 2011 Energy Conversion Congress and Exposition, 2011, pp. $568-575$.

[2] Z. Zhou, P. Holland, and P. Igic, "Compact thermal model of a three-phase igbt inverter power module," in Microelectronics, 2008. MIEL 2008. 26th International Conference on, May 2008, pp. 167-170.

[3] Zelnik R., Prazenica M.; "Multiple Output Flyback Converter Design" In: TRANSACTIONS ON ELECTRICAL ENGINEERING, Vol. 8, No. 3, pp. 32- 39, 2019.

[4] J. Antonios, N. Ginot, C. Batard, "Electrothermal investigations on silicon inverters operating at low frequency," in $201111^{\text {th }}$ International Thermal, Mechanical \& MultiPhysics Simulation, and Experiments in Microelectronics and Microsystems (EuroSimE)

[5] Cubon, Peter; Sedo, Jozef; Radvan, Roman; "Calculation of demand of electric power of 
small electric vehicle using Matlab GUI" et al. 2014 ELEKTRO Pages: 149-153 Published: 2014

[6] R. B. B. Ovando, N. Ramirez, C. Hernandez, "A 2D finite element thermal model of a threephase inverter heat sink," in 2010 IEEE Electronics, Robotics and Automotive Mechanics Conference

[7] Spanik, P.; Cuntala, J.; Frivaldsky; "Investigation of Heat Transfer of Electronic System through Utilization of Novel Computation Algorithms" M.; et al. ELEKTRONIKA IR ELEKTROTECHNIKA

[8] Frivaldsky, Michal; Spanik, Pavol; Drgona, Peter; "Algorithms for indirect investigation of heat distribution in electronic systems" et al. INTERNATIONAL JOURNAL OF THERMAL SCIENCES

Volume: 114 Pages: 15-34 Published: APR 2017

[9] Spanik, P.; Dobrucky, B.; Frivaldsky; "Measurement of swtitching losses in power transistor structure", M.; et al. ELEKTRONIKA IR ELEKTROTECHNIKA Issue: 2 Pages: 75-78 Published: 2008

[10] Paskala, Marek; Pridala, Michal; Pipiska, Michal; "The Support System for Testing the Power Converters The system of water cooling / heating" et al. 2016 ELEKTRO 11TH INTERNATIONAL CONFERENCE Pages: 196-200 Published: 2016

[11] Casanellas. F., "Losses in PWM inverters using IGBTs," IEE Proc. Electr. Power App1.,1994, 141, pp.235-239.

[12] M.H. Bierhoff and F.W. Fuchs, "Semiconductor Losses in Voltage Source and Current Source IGBT Converters Based on Analytical Derivation," Proceedings of the 2004 IEEE Power Electronics Specialist Conference (PESC04), pp.2836-2842, 2004L. K. Mestha, P. D. Evans, "Analysis of on-state losses in PWM Inverters," Proc. IEEE-Elect. Power Apjdicat., Vol. 136,110.4, . 189-195, 1989.
[13] Dr. Dusan Graovac, Marco Purschel, Infineon Technologies; "IGBT Power Losses Calculation Using the Data-Sheet Parameters" Available:https://www.element14.com/commu nity/servlet/JiveServlet/download/20553-13493/IGBT\%20Power\%20Losses\%20Calculati on\%20using\%20the\%20Data\%20Sheet\%20Par ameters.pdf

[14] A. Khoskhbar Sadigh, V. Dargahi and K. Corzine, "Calculation of conduction power losses in double flying capacitor multicell converter," 2015 IEEE Applied Power Electronics Conference and Exposition (APEC), Charlotte, NC, 2015, pp. 2351-2357, doi: 10.1109/APEC.2015.7104677.

[15] M. A. Dybko, S. S. Turnaev and S. V. Brovanov, "A power losses calculation in a four-legged threelevel voltage source inverter," 2009 International Conference and Seminar on Micro/Nanotechnologies and Electron Devices, Novosibirsk, 2009, pp. 365-369, doi: 10.1109/EDM.2009.5174013.

[16] Chouya,A. Chenafa,M. Mansouri,A. "Sensorless speed high gain observer based on field-oriented control for the asynchronous machine" In: WSEAS Transactions on Power Systems, Vol.13, pp.125-134, 2018

[17] Mitsubishi Electric Corporation, " $7^{\text {th }}$ Generation IGBT Module T/T1 - Series Application Note".Available: http://www.mitsubishielectric.com/semiconduc tors/files/manuals/igbt_t_note_e.pdf

\section{Creative Commons Attribution License 4.0 (Attribution 4.0 International, CC BY 4.0)}

This article is published under the terms of the Creative Commons Attribution License 4.0 https://creativecommons.org/licenses/by/4.0/deed.en US 